164

\section{DIAGNOSI DI ASPERGILLOSI INVASIVA SU SIERO MEDIANTE ESTRAZIONE CON SISTEMA MINIMAG E REAL-TIME PCR}

Bassani L. ${ }^{3}$, Colombrita D.', Minini C. ${ }^{3}$, Draghin E.', Fiorentini S. ${ }^{3}$ Foresti I.' , Garrafa E. ${ }^{3}$, Cattaneo C. ${ }^{2}$, Bottelli C. ${ }^{2}$, Rossi G. ${ }^{2}$, Caruso A. ${ }^{3}$.

'Servizio di Microbiologia, P. O. Umberto ${ }^{\circ}$ A. O. Spedali Civili, Brescia ${ }^{2}$ U. O. Ematologia, Spedali Civili, Brescia

${ }^{3}$ Sezione Microbiologia, Università degli Studi, Brescia

Introduzione. La diagnosi di Aspergillosi invasiva mediante RT-PCR, presenta ancor oggi notevoli difficoltà. In questo studio, oltre a verificare la validità di 4 metodi di estrazione su ceppi di Aspergillus fumigatus, abbiamo utilizzato quello risultato più valido, sul siero di pazienti ematologici, con successiva amplificazione-rivelazione con RT-PCR, per la diagnosi di Aspergillosi invasiva.

Metodi. Per l'estrazione del DNA sono stati saggiati i metodi Qiamp DNA blood minikit (Qiagen), High Pure PCR template preparation kit (Roche), Extracell (Amplimedical) e Nuclisens con sistema semiautomatico Minimag (bioMerieux). Con quest'ultimo abbiamo ottenuto una maggiore sensibilità e lo abbiamo utilizzato per estrarre il DNA da 146 sieri di 37 pazienti ematologici. Successivamente questi sono stati amplificati e rivelati in Real-Time PCR, grazie all'utilizzo di una sonda Taqman, specifica per il genere Aspergillus, disegnata, usando il software Primer Express, all'interno di una regione conservata del gene $18 \mathrm{~S}$ rRNA. Trenta sieri ottenuti da volontari sani, sono stati valutati come controllo. Infine i risultati ottenuti in Real-Time sono stati confrontati con quelli ottenuti con il test del Galattomannano e con i criteri dell'EORTC.

Risultati. Tutti i volontari sani sono risultati negativi. Secondo i criteri EORTC, abbiamo classificato 6 pazienti con 'probabile' Aspergillosi, 20 con "possibile" e 11 con diagnosi "negativa". Il test del Galattomannano (GM) è risultato positivo in $3 / 6$ pazienti con 'probabile' in $2 / 20$ con 'possibile', in $0 / 11$ con nessuna infezione. La RT-PCR è stata positiva in 5/6 'probabili', 9/20 "possibili" e 2/11 con nessuna infezione. In $3 / 5$ pazienti con 'probabile' infezione, la RT-PCR è risultata positiva più precocemente rispetto al GM.

Conclusioni. La RT-PCR per la diagnosi di Aspergillosi invasiva, ha mostrato buona sensibilità e un alto valore predittivo negativo. Soprattutto potrebbe essere un marcatore precoce di infezione fungina, sebbene questi risultati debbano essere confermati su un numero più ampio di pazienti.

\section{5}

\section{VALUTAZIONE DELLA RESISTENZA ALLA CLARITROMICINA MEDIANTE PCR IN PAZIENTI INFETTATI DA HELICOBACTER PYLOR}

\author{
Caldarelli S.R., Verona L., Menin E., Molina V. \\ CAM, Centro Analisi Monza, Sezione di Microbiologia.
}

Introduzione. Helicobacter pylori $(\mathrm{Hp})$ è un batterio Gramnegativo, microaerofilo, che produce notevoli quantità di urea, difficilmente coltivabile in laboratorio.

L'infezione è diffusa in tutto il mondo, ed è associata a patologie gastro-enteriche acute e croniche, tra cui il carcinoma gastrico.

La terapia farmacologica per l'eradicazione dell'infezione, secondo la Conferenza di Maastricht del 2005, si basa sull'utilizzo di claritromicina associata ad amoxicillina. Purtroppo, esiste una resistenza diffusa alla claritromicina, con percentuale variabile nei diversi Paesi, che non supera il $20 \%$ in Italia.

Generalmente la diagnosi di infezione viene effettuata mediante indagini sierologiche e/o Breath test e poi confermata da analisi della biopsia gastrica, senza quindi che venga effettuato un antibiogramma.

Metodi. Lo scopo di questa ricerca è quindi di mettere a punto una metodica diagnostica semplice, non invasiva e poco costosa, per la diagnosi di infezione da Hp e per la ricerca della resistenza alla claritromicina. Questa è dovuta a mutazioni puntiformi di due nucleotidi adiacenti nella regione conservata $23 S$ rRNA.

Abbiamo messo a punto una PCR che amplifica la regione $23 S$ rRNA su campioni di feci, da cui è stato estratto preliminarmente il DNA.

L'estrazione di DNA si è rivelata inizialmente abbastanza difficoltosa per la presenza di diverse sostanze inibitrici e per verificarne la qualità abbiamo utilizzato il gene APC come controllo interno di PCR.

Risultati. I risultati ottenuti dimostrano un'alta percentuale di pazienti resistenti alla claritromicina (37\%) rispetto ai dati presenti in letteratura.

Conclusioni. In definitiva, la PCR per la regione $23 S \mathrm{r} R N A$ potrebbe essere utilizzata sia per la diagnosi di infezione che per l'analisi della presenza di resistenza alla claritromicina. 